\title{
Erratum to: Effects of different selenium levels on growth and regulation of laccase and versatile peroxidase in white-rot fungus, Pleurotus eryngii
}

\author{
Yong Hyun Kim • Hyoun-Su Lee $\cdot$ Hyun-Jung Kwon • \\ Bharat Bhusan Patnaik $\cdot$ Kung-Woo Nam • \\ Yeon Soo Han · In-Seok Bang • Man-Deuk Han
}

Published online: 23 April 2014

(C) Springer Science+Business Media Dordrecht 2014

\section{Erratum to: World J Microbiol Biotechnol}

\section{DOI 10.1007/s11274-014-1636-x}

Unfortunately, in the original publication author had missed to acknowledge the financial grant statement. It has been provided below.

Acknowledgments This study was supported, in part, by the Soonchunhyang University Research Fund.

The online version of the original article can be found under doi:10.1007/s11274-014-1636-x.

Y. H. Kim · H.-S. Lee · H.-J. Kwon · K.-W. Nam •

M.-D. Han ( $\square)$

Department of Biology, Soonchunhyang University, Asan,

Chungnam 336-745, Republic of Korea

e-mail:mdhan@sch.ac.kr

B. B. Patnaik · Y. S. Han

Division of Plant Biotechnology, College of Agriculture and Life

Science, Chonnam National University, Kwangju 500-757,

Republic of Korea

I.-S. Bang

Department of Biological Science, Hoseo University, Asan,

Chungnam 330-713, Republic of Korea 